\title{
Twelve year trajectories of physical activity and health costs in mid-age Australian women
}

\author{
Grace A. O. Gomes ${ }^{1,2^{*}}$ (D) Wendy J. Brown², Jamile S. Codogno ${ }^{3}$ and Gregore I. Mielke ${ }^{2}$
}

\begin{abstract}
Background: Few studies have examined relationships between physical activity (PA) during mid-age and health costs in women. The aim of this study was to investigate associations between PA levels and trajectories over 12 years with medical and pharmaceutical costs in mid-age Australian women.

Methods: Data from 6953 participants in the Australian Longitudinal Study on Women's Health (born in 19461951) were analysed in 2019. PA was self-reported in 2001 (50-55y), 2007 (56-61y) and 2013 (62-67y). PA data were linked with 2013-2015 data from the Medicare (MBS) and Pharmaceutical (PBS) Benefits Schemes. Quantile regression was used to examine associations between PA patterns [always active, increasers, decreasers, fluctuaters or always inactive (reference)] with these medical and pharmaceutical costs.

Results: Among women who were consistently inactive (<500 MET.minutes/week) in 2001, 2007 and 2013, median MBS and PBS costs (2013 to 2015) were AUD4261 and AUD1850, respectively. Those costs were AUD1728 (95\%Cl: 443-3013) and AUD578 (95\%Cl: 426-729) lower among women who were consistently active in 2001, 2007 and 2013 than among those who were always inactive. PBS costs were also lower in women who were active at only one survey (AUD205; 95\%Cl: 49-360), and in those whose PA increased between 2001 and 2013 (AUD388; 95\%Cl: 232-545).

Conclusion: Maintaining 'active' PA status was associated with 40\% lower MBS and 30\% lower PBS costs over three years in Australian women. Helping women to remain active in mid-life could result in considerable savings for both women and the Australian government.
\end{abstract}

Keywords: Exercise, Behavior, Health care costs, Health expenditures, Middle aged, Older adults

\section{Background}

The health benefits of physical activity (PA) are well known; they include prevention and control of weight gain, non-communicable diseases and mental health problems [1, 2]. Despite these benefits, it is estimated that globally only one in four adults achieve the current

\footnotetext{
* Correspondence: graceaogomes@yahoo.com.br

'Department of Gerontology, Federal University of São Carlos, Rod. Washington Luiz, s/n, São Carlos, SP 13565-905, Brazil

${ }^{2}$ School of Human Movement and Nutrition Sciences, The University of Queensland, St Lucia QLD, Brisbane, Queensland 4072, Australia

Full list of author information is available at the end of the article
}

PA guidelines [3, 4], and women are more inactive than men in most countries [3-5].

Although maintaining PA at recommended levels over time is essential for women's health, PA levels change continually across the lifespan. Data from the Australian Longitudinal Study on Women's Health show that when women transition from ages 50-55 to 53-58, only one third maintain recommended levels of PA over 3 years, whereas one third remain inactive, and one third change from active to inactive or vice-versa [6]. Moreover, there are marked declines in PA among young married

(c) The Author(s). 2020 Open Access This article is licensed under a Creative Commons Attribution 4.0 International License, which permits use, sharing, adaptation, distribution and reproduction in any medium or format, as long as you give appropriate credit to the original author(s) and the source, provide a link to the Creative Commons licence, and indicate if changes were made. The images or other third party material in this article are included in the article's Creative Commons licence, unless indicated otherwise in a credit line to the material. If material is not included in the article's Creative Commons licence and your intended use is not permitted by statutory regulation or exceeds the permitted use, you will need to obtain permission directly from the copyright holder. To view a copy of this licence, visit http://creativecommons.org/licenses/by/4.0/ The Creative Commons Public Domain Dedication waiver (http://creativecommons.org/publicdomain/zero/1.0/) applies to the data made available in this article, unless otherwise stated in a credit line to the data. 
women with children, mirroring the constraints imposed on available time for PA, due to paid and unpaid work commitments. Following retirement from the paid workforce, and when children leave home, some women increase their PA, but in older age PA levels tend to decrease as health problems increase [3, 6-9]. Overall, there is a trend of declining PA with increasing age; both are associated with worsening health outcomes [10].

Recently published research has shown that mid-age and older adults can gain substantial health benefits by becoming more active, regardless of past PA levels and established risk factors [11-13]. Other studies have shown positive impacts of becoming more active on intermediate health outcomes at older age, such as physical function [14], joint symptoms [15] and cognitive function [16]. These positive effects may influence utilization of health services in later years, and consequently, the costs. Although several cross-sectional studies support the evidence of associations between PA and use and costs of health services [17-21], only one US study [22] and two previous analyses of ALSWH data $[23,24]$ have examined these relationships prospectively.

Longitudinal associations between PA levels and trajectories with health costs among mid-age women are still largely unexplored. Therefore, the aim of this study was to investigate PA levels and trajectories over 12 years (when the women were in their early 50 s to mid$60 \mathrm{~s})$ and their associations with medical and pharmaceutical costs 3 years later among Australian women. We hypothesized that being more physically active during mid-age would be associated with lower medical and pharmaceutical costs in later life.

\section{Methods \\ Design and participants}

This study used data from the mid-age cohort (born in 1946 to 1951) of the Australian Longitudinal Study on Women's Health (ALSWH), an ongoing study of Australian women. Baseline surveys were mailed in 1996 when women were $45-50$ years old $(N=13,714)$, with follow up surveys from 1998 to 2016 at 3 year intervals. At baseline, the sample was largely representative of Australian women in this age group, but with a somewhat higher representation of partnered women and women with post-high school education [25]. Ethics approval for the study was gained from the relevant ethics committees at the University of Newcastle (No. H-2010_0031) and the University of Queensland (No. 2010000411). Participants gave their informed consent to participate. Further details of the recruitment methods and response rates and data collection have been described elsewhere [25]. For this study, we analysed data from women with PA data in 2001 (50-55y), 2007 (56-61y) and 2013 (62-
$67 y)$, and who consented to linkage with healthcare administrative data $(N=6953)$.

\section{Physical activity}

Physical activity (explanatory variable) was assessed in 2001, 2007 and 2013 using a modified version of the Active Australia questionnaire, which has acceptable reliability and validity for use in cohort studies [26]. Participants were asked about frequency and duration of walking briskly (for recreation or exercise or to get to or from places), moderate-intensity leisure- activities (like social tennis, moderate exercise classes, recreational swimming, dancing), and vigorous-intensity leisure-time activities (that make you breathe harder or puff and pant) in the last week. They were asked to only report PA that lasted $10 \mathrm{~min}$ or more. Minutes per week spent in each activity were multiplied by a metabolic equivalent (MET) score: 3.33 for walking and moderate intensity leisure activities and 6.66 for vigorous leisure-time activity. The amount of PA was calculated as the sum of MET-minutes/week from each of the domains and categorised as: none $(0-<33.3$; reference category); low $(33.3-<500)$; moderate $(500-<1000)$; or high $(\geq 1000)$ [27].

\section{Costs of health services}

Health costs data from the Australian Medicare Benefits Scheme (MBS) and the Pharmaceutical Benefits Scheme (PBS) were the outcome measures for these analyses. Total health costs, which include the government benefits paid and the out-of-pocket costs paid by the patient for each service (MBS) or prescription (PBS), were calculated for each participant as the sum of total costs from 2013 (62-67y) to 2015 (64-69y). MBS is the Australian government's system for subsidising general practitioner and some out-of-hospital specialist, pathology, radiology, dental and allied health services, and limited additional primary healthcare services, for all Australian citizens and permanent residents (MBS, 2019) [28]. PBS is the system that subsidises the cost of approved prescribed medications.

\section{Covariables}

In 2013, participants provided information on age, area of residence, education, marital status, smoking, alcohol, and perceived health. Alcohol status was based on questions about frequency and quantity of alcohol intake [29] and all variables were categorised as shown in Table 1 . The women were also asked whether they had a health care card (which allows disadvantaged patients lower out-of-pocket costs). Body Mass Index (BMI) was categorized according to the World Health Organization classification: underweight $\left(\mathrm{BMI}<18.5 \mathrm{~kg} / \mathrm{m}^{2}\right)$; normal weight (BMI 18.5-24.9 $\mathrm{kg} / \mathrm{m}^{2}$ ), overweight (BMI 25.0- 
Table 1 Sociodemographic and health characteristics of the analytical sample in 2013, and health costs in 2013-2015, according to sociodemographic and health characteristics $(N=6953)$

\begin{tabular}{|c|c|c|c|c|}
\hline \multirow[t]{2}{*}{ Characteristics } & \multirow[b]{2}{*}{$\mathrm{N}$} & \multirow[b]{2}{*}{$\%$} & \multicolumn{2}{|c|}{ Health Costs 2013-2015 (AUD) ${ }^{a}$} \\
\hline & & & $\begin{array}{l}\text { MBS }^{\mathbf{b}} \\
\text { Median (25th -75th) }\end{array}$ & $\begin{array}{l}\text { PBS }^{\mathrm{c}} \\
\text { Median (25th -75th) }\end{array}$ \\
\hline \multicolumn{5}{|l|}{ Area of residence } \\
\hline Urban & 2694 & 39.3 & 4275 (2089-7816) & $1156(303-2647)$ \\
\hline Rural & 3927 & 57.3 & 3645 (1849-6624) & $1330(360-2991)$ \\
\hline Remote & 233 & 3.4 & $2169(208-5244)$ & $883(0-2358)$ \\
\hline \multicolumn{5}{|l|}{ Education } \\
\hline No f ormal education & 743 & 11.5 & $3833(1942-6775)$ & $1744(585-3498)$ \\
\hline School certificate & 3052 & 47.2 & 3816 (1930-7016) & $1391(400-3067)$ \\
\hline Higher school certificate & 2666 & 41.2 & $3582(1747-6791)$ & $905(185-2321)$ \\
\hline \multicolumn{5}{|l|}{ Marital status } \\
\hline Married/de facto & 5245 & 75.8 & 3802 (1877-7028) & $1217(309-2730)$ \\
\hline Separated/divorced/widowed & 1497 & 21.6 & $3762(1778-6871)$ & $1358(328-3225)$ \\
\hline Never married & 177 & 2.5 & 4189 (2151-8174) & $1313(294-3089)$ \\
\hline \multicolumn{5}{|l|}{ Health care cards } \\
\hline Yes & 3302 & 47.6 & 4076 (2029-7409) & $1788(294-3089)$ \\
\hline No & 3626 & 52.3 & 3579 (1714-6665) & $828(172-2093)$ \\
\hline \multicolumn{5}{|l|}{ Body mass index } \\
\hline Underweight / Normal & 2438 & 36.2 & $3463(1655-6453)$ & $711(135-1906)$ \\
\hline Overweight & 2292 & 34.1 & 3692 (1783-6757) & $1254(321-2616)$ \\
\hline Obese & 1992 & 29.6 & 4437 (2235-7975) & $2096(871-4090)$ \\
\hline \multicolumn{5}{|l|}{ Smoking status } \\
\hline Never-smoked & 4374 & 63.1 & 3801 (1871-7015) & $1155(284-2621)$ \\
\hline Ex-smoker & 2125 & 30.6 & 3891 (1946-7132) & $1353(370-3104)$ \\
\hline Smoker & 431 & 6.2 & 3315 (1361-6276) & $1649(429-4041)$ \\
\hline \multicolumn{5}{|l|}{ Alcohol } \\
\hline Low risk drinker & 3849 & 55.7 & 3626 (1794-6834) & $1011(242-2329)$ \\
\hline Non-drinker & 1084 & 15.7 & 4064 (1951-7562) & 1781 (457-3979) \\
\hline Rarely drinks & 1560 & 22.6 & 4080 (1968-7562) & $1532(429-3390)$ \\
\hline Risky/high risk drinker & 411 & 5.9 & $3544(1601-6428)$ & $1346(461-2879)$ \\
\hline \multicolumn{5}{|l|}{ Self-reported health } \\
\hline Excellent/very good & 3342 & 48.1 & $2946(1440-5519$ & $668(125-1698)$ \\
\hline Good & 2707 & 39.0 & 4273 (2236-7537) & $1690(623-3381)$ \\
\hline Fair/poor & 891 & 12.8 & $6530(3540-10,988)$ & 3812 (1658-7125) \\
\hline \multicolumn{5}{|c|}{ Number of chronic health conditions } \\
\hline 0 & 1301 & 19.6 & $2076(967-4011)$ & $214(33-813)$ \\
\hline $1-2$ & 3671 & 55.3 & $3590(1868-6430)$ & $1137(352-2272)$ \\
\hline$\geq 3$ & 1663 & 25.0 & $5931(3331-9964)$ & 3015 (1530-5582) \\
\hline
\end{tabular}

${ }^{\mathrm{a}} \mathrm{AUD}=$ Total health costs over three years in Australian Dollars (2013-2015);

${ }^{\mathrm{b}} \mathrm{MBS}=$ Medical Benefits Scheme;

c $\mathrm{PBS}=$ Pharmaceutical Benefits Scheme

$\left.29.9 \mathrm{~kg} / \mathrm{m}^{2}\right)$ or obese $\left(\mathrm{BMI} \geq 30 \mathrm{~kg} / \mathrm{m}^{2}\right)$. In each survey, women were asked "In the past three years, have you been diagnosed or treated for..." followed by a list of conditions which are common in mid-age women (including arthritis, diabetes, heart disease, asthma, breast and colon cancer, depression, anxiety etc). Copies of the surveys are available at www.alswh.org/ surveys. 


\section{Data analysis}

Sociodemographic and behavioural characteristics of the analytical sample in 2013 were summarized using descriptive statistics (eg proportions, medians and Interquartile ranges $-\mathrm{IQRs}$ ). Median and IQRs were calculated for MBS and PBS health costs during 20132015 according to sociodemographic characteristics in 2013.

For the trajectory analyses women were categorised as either 'inactive' (none or low) or 'active' (moderate or high) at each survey. The proportion of active women at each survey was calculated and changes in activity status (active/inactive) between 2001 and 2007 and between 2007 and 2013 were computed and illustrated using a lasagne plot [30]. To elucidate the associations between physical activity and health costs, the analyses were conducted in four steps. First, median and interquartile ranges for total MBS and PBS costs in 2013-2015 were calculated for each physical activity category in 2001, 2007 and 2013. Second, costs were calculated for five groups according to PA trajectories: a) always inactive (inactive in all three surveys); b) always active (active in all three surveys); c) increasers (changed from inactive in 2001 to active in 2013); d) decreasers (changed from active in 2001 to inactive in 2013); e) 'fluctuaters' (classified in the same PA category in 2001 and 2013, but in the opposite category in 2007). Third, a cumulative PA score was created by summing the number of times women were categorized as active $(0,1,2$ or 3$)$ and costs were calculated for women in each of these categories. Fourth, crude and adjusted quantile regression models were used to estimate the differences in median costs for each of the PA variables described in steps one to three. Analyses were adjusted for confounders that have been shown in previous ALSWH studies to be associated with both PA and health costs $[15,24,31]$. These included age, education, marital status, area of residence, having a health care card, smoking, alcohol and BMI. Associations between physical activity trajectories and sociodemographic and health characteristics are shown in Supplementary Table 1. Number of chronic conditions was not included in the regression models because many of the chronic conditions could be mediators of the association between PA and medical and pharmaceutical costs. All statistical analyses were performed using Stata 16.1 in 2019.

\section{Results}

Of the 13,714 women who were age $45-50$ years when the cohort was established in 1996, 12,707 (92.7\%) consented to data linkage. Of these, 4915 women did not complete at least one of the three surveys $(2001,2007$, and 2013) and 839 were excluded because they had missing information for PA in one or more surveys. The analytical sample included 6953 women (Supplementary Figure 1).

The women's sociodemographic and health characteristics are presented in Table 1 . Their average age in 2013 was 64.5 (range 62-67 years), nearly two thirds were overweight/obese, $6 \%$ were current smokers and one quarter had three or more chronic health conditions. Those whose data were included in the analyses were more likely to have post-school education, excellent/very good perceived health and to be active, and less likely to have a health care card, than those who were not included in the analyses due to loss-to-follow up or missing data $(n=6761)$. (Supplementary Table 2$)$.

The distributions of PA at each survey are presented in Fig. 1, and PA trajectories are shown in the middle panel of Table 2. Approximately half the women were active in 2001. This proportion increased by 13 percentage points from 2001 to 2007 (64.1\%), then remained fairly stable from 2007 to 2013 (62.9\%). More than half the women changed their PA status over the three time points, about one third were active, and $15.7 \%$ were inactive at all three surveys. One in four women increased their PA from 2001 to 2013, whereas 13\% decreased their PA in this period; $22.4 \%$ were active in only one of the three surveys.

The median MBS and PBS costs from 2013 to 2015 were AUD3,788 (IQR: 1859-7015) and AUD1245 (IQR: 315-2843) respectively. Overall, these costs were consistently higher among women in the lowest PA category, at every survey (see top panel of Table 2). The median costs were higher among women who were always inactive than in those who were always active. Costs were markedly lower in the increasers than in the decreasers or fluctuaters (see centre panel of Table 2). Both MBS and PBS costs declined with increasing numbers of surveys in which women were categorized as active (see bottom panel of Table 2).

Differences in median 3 year costs between categories of PA in each survey (2001, 2007 and 2013), PA trajectories, and the number of surveys women were active, are presented in Table 3. In adjusted models, median MBS costs were similar across the PA categories in 2001 and 2007, but in 2013 costs decreased with increasing PA. The median cost was AUD3,522 (95\%CI: 22124831) lower in women with high levels of PA in 2013 than among women who were inactive. In women who were always active, costs were AUD1,728 lower than in those who were always inactive (across three surveys in 12 years; see middle panel of Table 3 ).

At each survey, women who reported at least low levels of physical activity had lower PBS costs from 2013 to 2015 than women who were inactive (Table 3), and costs decreased further with increasing PA category. In the trajectory analyses, PBS costs were AUD578, 


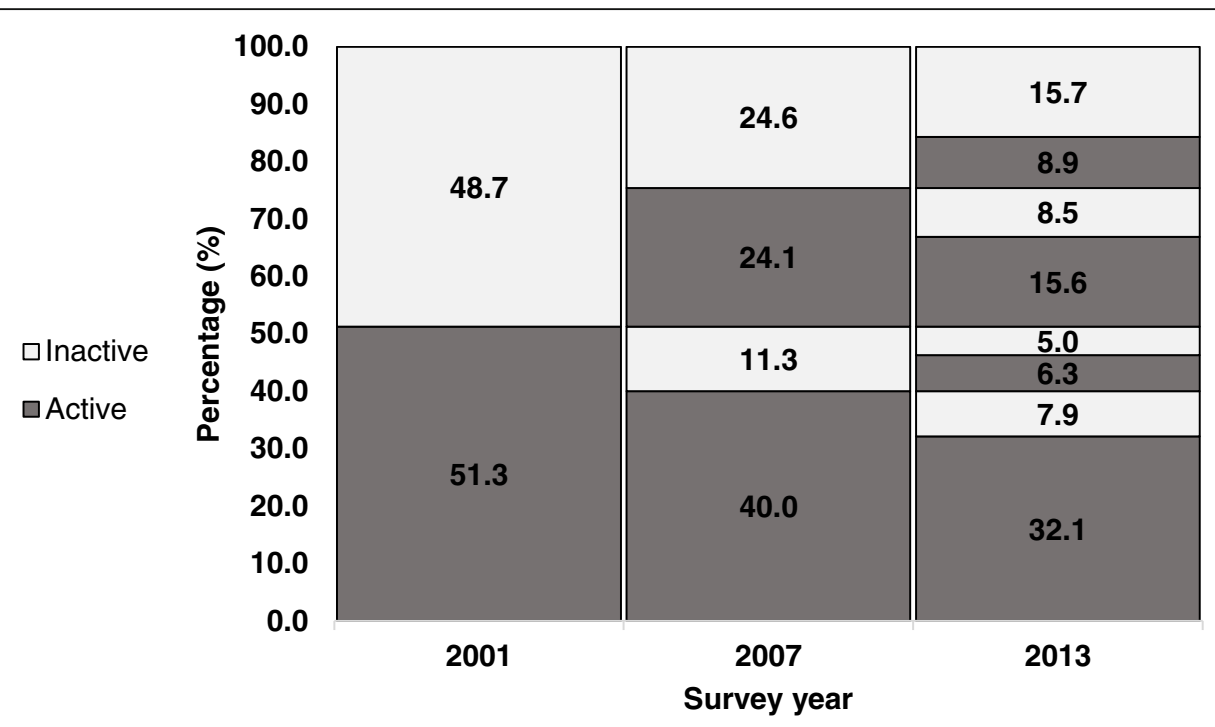

Fig. 1 Lasagne plot to illustrate changes in physical activity category $(2001,2007,2013)$ in mid-age women ( $N=6953)$. The data show, for example, that $11.3 \%$ of women were active in 2001 but inactive in 2007, and $7.9 \%$ were active in the first two surveys and inactive in 2013 , etc.

AUD388, and AUD260 lower in women who were always active, those who increased PA levels and 'fluctuaters' over 12 years, respectively, than for women who were always inactive. There was a dose-response relationship between number of surveys that women were active and PBS savings. Women who were active in at least one survey had AUD205 lower PBS costs from 2013 to 2015 than women who were always inactive (see bottom panel of Table 3).

\section{Discussion}

This study provides novel insights into levels and trajectories of physical activity during mid-age and their associations with health costs in mid-age Australian women. Our findings show an overall increase in PA levels from 2001 (50-55 years) to 2007 (56-61), which was maintained in 2013 (62-67). Consistent with previous studies, fewer than half the participants remained in the same PA category over 12 years, but those who were consistently active in this period had lower MBS and PBS costs than those who were inactive.

Our findings are consistent with reports from several studies conducted in other countries, which have shown inverse relationships between PA and health costs [19, 32-37]. However, no previous studies have examined the costs associated with trajectories and changes in PA. This is important, because physical activity changes throughout the lifespan, often in parallel with important life events (e.g. having a baby or widowhood) and changing social circumstances (e.g. paid work, retirement) [6, 38-41]. In contrast with our finding that only one third of these mid-age women were consistently active, Smith et al. [9] reported that almost half (49\%) of those over 65 years in a UK sample were persistently active over 10 years. However, differences in the number of time points at which PA is measured, as well as in the instruments used, and the age and gender of participants, mean that comparisons should be made with caution.

Because of substantial increases in the use of healthcare resources in recent decades, in particular among older populations, governments worldwide are attempting to determine strategies for controlling utilization of healthcare and consequent health costs [42, 43]. Focussing on PA in mid-age may be particularly important, because this is a life-stage when risk of disability and complications from non-communicable diseases begin to increase. Our data suggest that strategies to increase physical activity in mid-age could save expenditure for governments, as well as for women themselves.

As the overall cost of inactivity internationally was estimated to be INT $\$ 53.8$ billion worldwide per annum in 2013 [34], one approach to reducing health costs may be to increase population levels of PA. Our findings show that maintaining high active status was associated with $30-40 \%$ lower costs after 12 years, in a period when health costs in Australia increased by 2.7 and 3.6\% for primary health care and hospitals, respectively [44, 45]. We estimated that $32 \%$ of women were always active and there were cost savings of AUD1728 for MBS and AUD578 for PBS every 3 years for these women. At the population level (with 2,914,000 women in the 50-69 years age group in Australia), and assuming there is a causal relationship in our analyses, we estimate that this would represent a saving of AUD2306 for 932,480 women, which equates to AUD2.15bn over 3 years. 
Table 2 Estimates of MBS and PBS costs in 2013-2015 according to physical activity indicators from 2001 to 2013 in mid-age Australian women $(N=6953)$

\begin{tabular}{|c|c|c|c|c|}
\hline \multirow{3}{*}{ Physical activity } & \multirow[b]{3}{*}{$\mathbf{N}$} & \multirow[b]{3}{*}{$\%$} & \multicolumn{2}{|c|}{ Health Costs (AUD) 2013-2015 } \\
\hline & & & \multirow{2}{*}{$\begin{array}{l}\text { MBS }^{\text {b }} \\
\text { Median (25th -75th) }\end{array}$} & \multirow{2}{*}{$\begin{array}{l}\text { PBS }^{\mathrm{C}} \\
\text { Median (25th -75th) }\end{array}$} \\
\hline & & & & \\
\hline \multicolumn{5}{|l|}{2001 (50-55 years) } \\
\hline None & 1047 & 15.1 & $4355(2204 ; 7774)$ & $1851(678 ; 4000)$ \\
\hline Low & 2341 & 33.6 & $3726(1895 ; 6936)$ & $1321(323 ; 2955)$ \\
\hline Moderate & 1575 & 22.7 & $3660(1787 ; 6675)$ & $1034(285 ; 2461)$ \\
\hline High & 1990 & 28.6 & $3737(1734 ; 6934)$ & $1026(212 ; 2500)$ \\
\hline \multicolumn{5}{|l|}{2007 (56-61 years) } \\
\hline None & 945 & 13.6 & $4355(2071 ; 7816)$ & $1991(717 ; 4351)$ \\
\hline Low & 1547 & 22.3 & $3697(1862 ; 6948)$ & $1306(325 ; 2985)$ \\
\hline Moderate & 1670 & 24.0 & $3741(1976 ; 6688)$ & $1264(328 ; 2697)$ \\
\hline High & 2791 & 40.1 & $3689(1722 ; 6880)$ & $999(221 ; 2424)$ \\
\hline \multicolumn{5}{|l|}{2013 (62-67 years) } \\
\hline None & 1135 & 16.3 & $4989(2534 ; 9217)$ & $2093(848 ; 4729)$ \\
\hline Low & 1448 & 20.8 & $3895(2030 ; 7134)$ & $1493(443 ; 3110)$ \\
\hline Moderate & 1468 & 21.2 & $3562(1830 ; 6632)$ & $1055(240 ; 2556)$ \\
\hline High & 2902 & 41.7 & $3444(1646 ; 6441)$ & $947(205 ; 2262)$ \\
\hline \multicolumn{5}{|l|}{ Trajectories of PA } \\
\hline Always inactive & 1092 & 15.7 & $4261(1991 ; 7623)$ & $1850(647 ; 4052)$ \\
\hline Always active & 2233 & 32.1 & $3448(1677 ; 6350)$ & $818(177 ; 2066)$ \\
\hline Increasers & 1702 & 24.4 & $3508(1765 ; 6661)$ & $1183(300 ; 2646)$ \\
\hline Decreasers & 897 & 13.0 & $4542(2226 ; 8219)$ & $1692(538 ; 3456)$ \\
\hline Fluctuaters & 1029 & 14.8 & $4170(2089 ; 7328)$ & $1460(367 ; 3224)$ \\
\hline \multicolumn{5}{|c|}{ Number of surveys as active } \\
\hline 0 & 1092 & 15.8 & $4261(1991 ; 7623)$ & $1850(647 ; 7458)$ \\
\hline 1 & 1559 & 22.4 & $4098(2225 ; 7644)$ & $1569(468 ; 3358)$ \\
\hline 2 & 2069 & 29.7 & $3823(1761 ; 6937)$ & $1216(315 ; 2768)$ \\
\hline 3 & 2233 & 32.1 & $3448(1677 ; 6350)$ & $818(177 ; 2066)$ \\
\hline
\end{tabular}

aUD: Health costs over three years in Australian Dollars (2013-2015)

${ }^{b}$ MBS: Medical Benefits Scheme

c PBS: Pharmaceutical Benefits Scheme

The strengths of this study include the use of a large population-based sample of mid-age women followed over 12 years, and linkage with government data on the costs of both medical and pharmaceutical services. The large analytical sample allowed us to estimate health costs for a range of trajectories of PA, after adjustment for established risk behaviors and sociodemographic characteristics that influence health costs. Further, the use of time lagged analyses showed consistent associations between low levels of PA at different time points and higher health costs some years later. Finally, because the PA trajectories (increasers, decreasers and fluctuaters) included different numbers of women who were active at each time, we also analysed the associations between PA patterns and health costs by the number of surveys the women were active; the results were only marginally changed.
As with all observational cohort studies, there are some limitations. Firstly, women whose data were included in the analyses were more educated and healthier than women in the original cohort; this may mean that our overall health cost estimates are underestimated. Secondly, self-reported PA is subject to recall and social desirability bias, which can overestimate the prevalence of 'active' women. These biases are likely to be nondifferential across the different levels of health costs, and would probably result in underestimation of the magnitude of the association between PA and health costs. Thirdly, while there was an element of 'time lag' in the analyses (ie PA data in 2001 and 2007 were linked with health cost data in 2013-2015), the associations between PA in 2013 and 2103-15 health costs may be subject to 
Table 3 Differences in median MBS and PBS costs (2013-2017) for categories of PA variables (levels and trajectories) from 2001 to 2013 in mid-age Australian women. ( $N=6953)$

\begin{tabular}{|c|c|c|c|c|}
\hline \multirow{3}{*}{ PA level } & \multicolumn{4}{|c|}{ 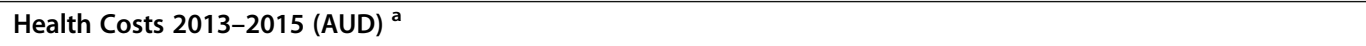 } \\
\hline & \multicolumn{2}{|l|}{ MBS $^{b}$} & \multicolumn{2}{|l|}{ PBS $^{c}$} \\
\hline & $\beta_{\text {crude }}(95 \% \mathrm{Cl})$ & $\beta_{\text {adjusted }}(95 \% \mathrm{Cl})^{d}$ & $\beta_{\text {crude }}(95 \% \mathrm{Cl})$ & $\beta_{\text {adjusted }}(95 \% \mathrm{Cl})^{d}$ \\
\hline \multicolumn{5}{|l|}{2001 (50-55 years) } \\
\hline None & 0 & 0 & 0 & 0 \\
\hline Low & $-628(-969 ;-287)$ & $-507(-1840 ; 825)$ & $-529(-690 ;-368)$ & $-363(-515 ;-211)$ \\
\hline Moderate & $-695(-1060 ;-329)$ & $-1106(-2537 ; 323)$ & $-817(-989 ;-644)$ & $-531(-694 ;-367)$ \\
\hline High & $-615(-965 ;-265)$ & $-719(-2096 ; 658)$ & $-823(-988 ;-657)$ & $-508(-665 ;-351)$ \\
\hline \multicolumn{5}{|l|}{2007 (56-61 years) } \\
\hline None & 0 & 0 & 0 & 0 \\
\hline Low & $-658(-1049 ;-267)$ & $-138(-1638 ; 1362)$ & $-684(-875 ;-493)$ & $-377(-541 ;-212)$ \\
\hline Moderate & $-612(-997 ;-226)$ & $-243(-1730 ; 1243)$ & $-727(-915 ;-538)$ & $-372(-535 ;-209)$ \\
\hline High & $-666(-1022 ;-310)$ & $-632(-2014 ; 749)$ & $-992(-1166 ;-818)$ & $-544(-696 ;-391)$ \\
\hline \multicolumn{5}{|c|}{2013 (62-67 years) } \\
\hline None & 0 & 0 & 0 & 0 \\
\hline Low & $-1090(-1448 ;-733)$ & $-2565(-4023 ;-1107)$ & $-598(-755 ;-442)$ & $-320(-485 ;-155)$ \\
\hline Moderate & $-1426(-1782 ; 1069)$ & $-3437(-4898 ;-1976)$ & $-1034(-1210 ;-858)$ & $-605(-771 ;-439)$ \\
\hline High & $-1544(-1860 ;-1228)$ & $-3522(-4831 ;-2212)$ & $-1145(-1301 ;-989)$ & $-669(-818 ;-519)$ \\
\hline \multicolumn{5}{|l|}{ PA trajectories } \\
\hline Always inactive & 0 & 0 & 0 & 0 \\
\hline Always active & $-813(-1148 ;-477)$ & $-1728(-3013 ;-443)$ & $-1032(-1195 ;-870)$ & $-578(-729 ;-426)$ \\
\hline Increasers & $-750(-1102 ;-397)$ & $-1117(-2448 ; 212)$ & $-666(-837 ;-495)$ & $-388(-545 ;-232)$ \\
\hline Decreasers & $281(-128 ; 690)$ & $1040(-499 ; 2579)$ & $-158(-357 ; 39)$ & $-130(-312 ; 50)$ \\
\hline Fluctuaters & $-91(486 ; 303)$ & $-434(-1919 ; 1049)$ & $-391(-582 ;-199)$ & $-260(-434 ;-86)$ \\
\hline \multicolumn{5}{|c|}{ Number of surveys active } \\
\hline 0 & 0 & 0 & 0 & 0 \\
\hline 1 & $-163(-540 ; 214)$ & $245(-1162 ; 1653)$ & $-282(-449 ;-114)$ & $-205(-360 ;-49)$ \\
\hline 2 & $-438(-796 ;-80)$ & $-811(-2152 ; 529)$ & $-634(-793 ;-475)$ & $-382(-530 ;-234)$ \\
\hline 3 & $-813(-1166 ;-459)$ & $-1771(-3112 ;-430)$ & $-1032(-1189 ;-875)$ & $-585(-734 ;-437)$ \\
\hline
\end{tabular}

aUD: Total health costs over three years in Australian Dollars (2013-2015)

${ }^{b}$ MBS: Medical Benefits Scheme

c PBS: Pharmaceutical Benefits Scheme

${ }^{\mathrm{d}}$ Adjusted for: Age, area, marital status, education, health card, smoking alcohol and BMI

reverse causation, whereby women who were ill in 2013 had lower PA in that year. This would also have affected the trajectory analyses and the cost estimates. Finally, even though numerous confounding variables were included in the analyses, there may have been residual confounding due to unmeasured variables.

Given the expected increased risks in chronic conditions and consequently higher health expenditures with increasing age, our results point to the utility of increasing PA in mid-age to reduce health care costs in older age, for both individuals and the government. Continued efforts to facilitate the implementation of population-based PA promotion strategies are needed. Moreover, more longitudinal studies with robust, objective PA and health costs measures would enhance our understanding of the effects of PA on utilization and costs of healthcare services.

Our findings provide insights into the associations between changing patterns of PA and health costs among mid-aged women. Australian women who were consistently active at this life stage had markedly lower MBS and PBS costs. We conclude that, to achieve health expenditure savings for women in their 50s and 60s, it would be necessary for low active women to become more active and for active women to remain active, for as long as is possible across the lifespan. It is not too late for women in their sixties to become more active and save costs for themselves as well as the health system. 


\section{Supplementary information}

Supplementary information accompanies this paper at https://doi.org/10. 1186/s12966-020-01006-6.

Additional file 1: Supplementary Table 1. Physical activity trajectories according to sociodemographic and health characteristics $(N=6,953)$. Supplementary Table 2. Comparison of sociodemographic, health conditions and physical activity levels in the analytical sample and those lost to follow up. (All data are from the baseline survey in 1996, unless indicated)

Additional file 2: Supplementary Figure 1. Flow diagram showing the selection of participants for inclusion, Australia, 2001-2013

\section{Abbreviations}

ALSWH: Australian longitudinal study on women's health; BMI: Body mass index; PA: Physical activity; PBS: Pharmaceutical benefits scheme; MBS: Medical benefits scheme

\section{Acknowledgments}

The research on which this paper is based was conducted as part of the Australian Longitudinal Study on Women's Health by researchers at the University of Queensland and the University of Newcastle. We are grateful to the Australian Government Department of Health for funding and to the women who provided the survey data. The authors acknowledge the Department of Health and Medicare Australia for providing MBS and PBS data, and the Australian Institute of Health and Welfare (AlHW) as the integrating authority.

\section{Authors' contributions}

WJB contributed to the design of the ALSWH and acquisition of data, GAOG, JSC, GIM and WJB were involved in the conception and design of this study, GAOG and GIM conducted the analyses, all authors were involved in interpretation of the data; GAOG prepared the first draft and all authors critically reviewed and revised this several times, with addition of important intellectual content. All authors gave final approval of the version to be submitted

\section{Funding}

The ALSWH is funded by the Australian Government Department of Health GAOG was supported by a fellowship (Research Scholarship Abroad-BPE) from the São Paulo Research Foundation (FAPESP) (grant number: 2018/ 12705-2). GIM was supported by a Development Fellowship from the University of Queensland. The organizations named here had no influence on the study design; the collection, analysis and interpretation of data; the writing of the report; or the decision to submit the article for publication.

\section{Availability of data and materials}

The data that support the findings of this study are available from the Australian Longitudinal Study on Women's Health, but restrictions apply to the availability of these data. De-identified survey data are available following an expression of interest (EOI) application through the ALSWH website (http://alswh.org.au/for-researchers) and approval by the ALSWH data access committee. The linked MBS and PBS data were used under license for the current study, and so are not publicly available. Linked analyses are also possible, subject to ALSWH EOI approval, but use of external linked datasets may only be conducted at the University of Queensland, the University of Newcastle or through the SURE facility at the Sax Institute https://www.saxinstitute.org.au/our-work/sure.

\section{Ethics approval and consent to participate}

Ethics approval for the study was gained from the relevant ethics committees at the University of Newcastle (No. H-2010_0031) and the University of Queensland (No. 2010000411). Participants gave their informed consent to participate.

\section{Consent for publication}

Not applicable.

\section{Competing interests}

The authors declare that they have no competing interests.

\section{Author details}

'Department of Gerontology, Federal University of São Carlos, Rod. Washington Luiz, s/n, São Carlos, SP 13565-905, Brazil. 'School of Human Movement and Nutrition Sciences, The University of Queensland, St Lucia QLD, Brisbane, Queensland 4072, Australia. ${ }^{3}$ Department of Physical Education, Presidente Prudente, São Paulo State University, R. Roberto Símonsen, 305 - Centro Educacional, Pres. Prudente, SP 19060-900, Brazil.

Received: 5 April 2020 Accepted: 29 July 2020

Published online: 10 August 2020

\section{References}

1. Lee IM, Shiroma EJ, Lobelo F, Puska P, Blair SN, Katzmarzyk PT, et al. Effect of physical inactivity on major non-communicable diseases worldwide: an analysis of burden of disease and life expectancy. Lancet. 2012;380(9838): 219-29.

2. Lear SA, Hu W, Rangarajan S, Gasevic D, Leong D, labal R, et al. The effect of physical activity on mortality and cardiovascular disease in 130000 people from 17 high-income, middle-income, and low-income countries: the PURE study. Lancet. 2017:390(10113):2643-54.

3. Sallis JF, Bull F, Guthold R, Heath GW, Inoue S, Kelly P, et al. Progress in physical activity over the Olympic quadrennium. Lancet. 2016;388(10051): 1325-36.

4. Guthold R, Stevens GA, Riley LM, Bull FC. Worldwide trends in insufficient physical activity from 2001 to 2016: a pooled analysis of 358 populationbased surveys with 1.9 million participants. Lancet Glob Health. 2018;6(10): 1077-86.

5. Mielke Gl, da Silva ICM, Kolbe-Alexander TL, Brown WJ. Shifting the physical inactivity curve worldwide by closing the gender gap. Sports Med. 2018; 48(2):481-9.

6. Brown WJ, Heesch KC, Miller YD. Life events and changing physical activity patterns in women at different life stages. Ann Behav Med. 2009:37(3):294305.

7. Brown WJ, Trost SG. Life transitions and changing physical activity patterns in young women. Am J Prev Med. 2003;25(2):140-3.

8. Kanesarajah J, Waller M, Whitty JA, Mishra GD. Physical activity and body mass shape quality of life trajectories in mid-age women. Aust NZ J Pub Health. 2018;42(4):403-9.

9. Smith L, Gardner B, Fisher A, Hamer M. Patterns and correlates of physical activity behaviour over 10 years in older adults: prospective analyses from the English longitudinal study of ageing. BMJ Open. 2015;5(4):e007423.

10. Brown W, Pavey T. Physical activity in mid-age and older women: lessons from the Australian longitudinal study on Women's health. Kinesiol Rev. 2016:5(1):87-97.

11. Elhakeem A, Murray ET, Cooper R, Kuh D, Whincup P, Hardy R. Leisure-time physical activity across adulthood and biomarkers of cardiovascular disease at age 60-64: a prospective cohort study. Atherosclerosis. 2018;269:279-87.

12. Saint-Maurice PF, Coughlan D, Kelly SP, Keadle SK, Cook MB, Carlson SA, et al. Association of Leisure-Time Physical Activity across the adult life course with all-cause and cause-specific mortality. JAMA Netw Open. 2019; 2(3):e190355.

13. Mok A, Khaw KT, Luben R, Wareham N, Brage S. Physical activity trajectories and mortality: population based cohort study. BMJ. 2019;365:12323.

14. Pettee Gabriel K, Sternfeld B, Colvin A, Stewart A, Strotmeyer ES, Cauley JA, et al. Physical activity trajectories during midlife and subsequent risk of physical functioning decline in late mid-life: the study of Women's health across the nation (SWAN). Prev Med. 2017;105:287-94.

15. Peeters GM, Pisters MF, Mishra GD, Brown WJ. The influence of long-term exposure and timing of physical activity on new joint pain and stiffness in mid-age women. Osteoarthr Cartil. 2015;23(1):34-40.

16. Hamer M, Muniz Terrera G, Demakakos P. Physical activity and trajectories in cognitive function: English longitudinal study of ageing. J Epidemiol Community Health. 2018;72(6):477-83.

17. Brown WJ, Hockey R, Dobson AJ. Physical activity, body mass index and health care costs in mid-age Australian women. Aust NZ J Publ Health. 2008;32(2):150-5.

18. Woolcott JC, Ashe MC, Miller WC, Shi P, Marra CA. Does physical activity reduce seniors' need for healthcare?: a study of 24281 Canadians. Br J Sports Med. 2010;44(12):902-4.

19. Kang SW, Xiang X. Physical activity and health services utilization and costs among U.S. adults. Prev Med. 2017;96:101-5. 
20. Lee IC, Chang CS, Du PL. Do healthier lifestyles lead to less utilization of healthcare resources? BMC Health Serv Res. 2017;17(1):243.

21. Chen IH, Chi MJ. Effects of self-care behaviors on medical utilization of the elderly with chronic diseases - a representative sample study. Arch Gerontol Geriat. 2015;60(3):478-85.

22. Andreyeva T, Sturm R. Physical activity and changes in health care costs in late middle age. J Phys Activ Health. 2006;3(s1):S6-s19.

23. Peeters GM, Mishra GD, Dobson AJ, Brown WJ. Health care costs associated with prolonged sitting and inactivity. Am J Prev Med. 2014;46(3):265-72.

24. Peeters G, Gardiner PA, Dobson AJ, Brown WJ. Associations between physical activity, medical costs and hospitalisations in older Australian women: results from the Australian longitudinal study on Women's health. J Sci Med Sport. 2018;21(6):604-8.

25. Dobson AJ, Hockey R, Brown WJ, Byles JE, Loxton DJ, McLaughlin D, et al. Cohort profile update: Australian longitudinal study on women's health. Int J Epidemiol. 2015;44(5):1547-f.

26. Brown WJ, Burton NW, Marshall AL, Miller YD. Reliability and validity of a modified self-administered version of the active Australia physical activity survey in a sample of mid-age women. Aust NZ J Public Health. 2008;32(6): $535-41$

27. Brown WJ, Bauman AE, Bull FC, Burton NW. Development of evidencebased physical activity recommendations for adults (18-64 years). Report prepared for the Australian Government Department of Health, August 2012. Available from: http://www.health.gov.au/internet/main/publishing. nsf/Content/health-pubhlth-strateg-phys-act-guidelines/\$File/DEB-PARAdults-18-64years.pdf. Accessed on $13^{\text {th }}$ June 2020.

28. Australian Government Department of Health. Medicare Benefits Schedule (MBS) 2019.Available from: http://www.mbsonline.gov.au/internet/ mbsonline/publishing.nsf/Content/Home. Accessed on $15^{\text {th }}$ Jan 2020.

29. National Health and Medical Research Council. Australian Alcohol Guidelines. Canberra, Australia: Australian Government Publishing Service; 2001.

30. Jones M, Hockey R, Mishra GD, Dobson A. Visualising and modelling changes in categorical variables in longitudinal studies. BMC Med Res Methodol. 2014 Dec;14(1):32.

31. Byles J, Mishra G, Hockey R, Adane A, Chan H, Dolja-Gore X, et al. Use, access to, and impact of Medicare services for Australian women: findings from the Australian longitudinal study on Women's health: The Australian Government Department of Health; 2017. Available from: https://www. alswh.org.au/images/content/pdf/major_reports/Major_Report_2017_Lay_ Summary_Web.pdf.

32. Yang G, Niu K, Fujita K, et al. Impact of physical activity and performance on medical care costs among the Japanese elderly. Geriatr Gerontol Int. 2011; 11(2):157-65.

33. Bueno DR, Marucci MFN, Rosa C, Fernandes RA, Duarte YAO, Lebrao ML. Objectively measured physical activity and healthcare expenditures related to arterial hypertension and diabetes mellitus in older adults: SABE study. Aging Phys Activ. 2017;25(4):553-8

34. Ding $\mathrm{D}$, Lawson $\mathrm{KD}$, Kolbe-Alexander $\mathrm{TL}$, et al. The economic burden of physical inactivity: a global analysis of major non-communicable diseases. Lancet. 2016;388(10051):1311-24

35. Bielemann RM, Knuth G, Hallal PC. Physical activity and cost savings for chronic diseases to the Sistema Único de Saúde. Braz J Phys Act Health. 2010:15:1-14.

36. Cadilhac DA, Cumming TB, Sheppard L, Pearce DC, Carter R, Magnus A. The economic benefits of reducing physical inactivity: an Australian example. Int J Behav Nutr Phys Act. 2011;8:99.

37. Zhang J, Chaaban J. The economic cost of physical inactivity in China. Prev Med. 2013;56(1):75-78.28

38. Leskinen T, Pulakka A, Heinonen OJ, Pentti J, Kivimaki M, Vahtera J, et al. Changes in non-occupational sedentary behaviours across the retirement transition: the Finnish retirement and aging (FIREA) study. J Epidemiol Community Health. 2018;72(8):695-701.

39. Pavey TG, Kolbe-Alexander TL, Uijtdewilligen L, Brown WJ. Which women are highly active over a 12-year period? A prospective analysis of data from the Australian longitudinal study on Women's health. Sports Med. 2017; 47(12):2653-66.

40. Szymczyk I, Wojtyna E, Lukas W, Kepa J, Pawlikowska T. How does gender influence the recognition of cardiovascular risk and adherence to self-care recommendations?: a study in polish primary care. BMC Fam Pract. 2013;14:165.

41. Hallal PC, Andersen LB, Bull FC, et al. Global physical activity levels: surveillance progress, pitfalls, and prospects. Lancet. 2012;380(9838):247-57.
42. Sommer I, Griebler U, Mahlknecht P, Thaler K, Bouskill K, Gartlehner G, et al. Socioeconomic inequalities in non-communicable diseases and their risk factors: an overview of systematic reviews. BMC Public Health. 2015;15:914.

43. Papanicolas I, Woskie LR, Jha AK. Health care spending in the United States and other high-income countries. JAMA. 2018;319(10):1024-39.

44. Australian Institute of Health and Welfare. Australia's Health Report 2004. Canberra: Australian Government; 2004. Available from: https:/www.aihw. gov.au/getmedia/5f8e9202-f733-45cd-80cb-e e58bba24afda/ah04- 050222. pdf.aspx?inline $=$ true. Accessed on: $15^{\text {th }}$ Jan 2020

45. Australian Bureau of Statistics. Australian Demographic Statistics. Estimated Population by Age and Sex (Jun 2019). Available from: https://www.abs.gov. au/AUSSTATS/abs@.nsf/DetailsPage/3101.0Jun\%202019?OpenDocument. Accessed on: 15 Jan 2020.

\section{Publisher's Note}

Springer Nature remains neutral with regard to jurisdictional claims in published maps and institutional affiliations.

Ready to submit your research? Choose BMC and benefit from:

- fast, convenient online submission

- thorough peer review by experienced researchers in your field

- rapid publication on acceptance

- support for research data, including large and complex data types

- gold Open Access which fosters wider collaboration and increased citations

- maximum visibility for your research: over $100 \mathrm{M}$ website views per year

At BMC, research is always in progress.

Learn more biomedcentral.com/submissions 